Alex Cistelecan

University of Medicine, Pharmacy, Science and Technology of Târgu Mureș

Târgu Mureș, Romania

altcistelecan@gmail.com

\title{
NOVEL AND ANTI-NOVEL. MORETTI BEFORE DISTANT READING
}

Recommended Citation: Cistelecan, Alex. "Novel and Anti-Novel. Moretti Before Distant Reading”. Metacritic Journal for Comparative Studies and Theory 6.2 (2020): https://doi.org/10.24193/mjcst.2020.10.01.

\begin{abstract}
The paper discusses an intermediary phase in Franco Moretti's intellectual journey, namely the 1990s. This is a period of transition in Moretti's thinking, in which he is working simultaneously on two fronts: on the one hand, he is refining and bringing to completion the style of close reading analysis he developed in the previous decade namely the combination of evolutionary theory, formal-rhetorical analysis, and eclectic Marxism (with its highly volatile mix of Lukács, Wallerstein, and Della Volpe); on the other, he is forging the tools and concepts of what would become, after 2000, his defining intellectual signature -distant reading. The two undertakings correspond to two opposed literary objects: on the one hand, the novel - with its regularity of form, large-scale reproduction, centripetal movement, bourgeois imaginary, and national focus; on the other, what we call the 'anti-novel', which is the modern epic in Moretti's understanding - the few dozen 'world-texts', highly polymorphous and reproducible only in few and select occurrences, centrifugal in their movement, and transcending the national and bourgeois perspectives, rooted as they are in the critical, semi-peripheral junctures of the capitalist world-system. The paper dwells on some of the oppositions and similarities, overlaps and contradictions, theoretical problems and practical solutions, raised or offered by the two methodological approaches and their corresponding literary objects.
\end{abstract}

Keywords: Franco Moretti, Distant Reading, Close reading, Novel, Modern Epic, World System 
In my attempt to reconstruct the evolution of Franco Moretti's thinking, ${ }^{1}$ it might have been more suitable to divide the work space into only two sections: close reading and distant reading. This would have meant that the first period (and, implicitly, section) would end around the mid-90's, with Opere mondo (1994 Italian ed., 1996 English ed. Modern Epic). The second would start immediately after, with Atlas of the European Novel (1997 Italian ed., 1998 the English one) and would last, if we include the long phase of increasing disenchantment with the paradigm, to the present day. See, for example, especially the 2019 and 2020 articles from New Left Review ${ }^{2}$ - however, it is true that they continue (and accentuate) a tendency towards methodological scepticism regarding distant reading, already visible in the early 2010's.

A two-section division would have been more logical and compact. Yet three sections make for a more dialectical approach. Organizing the evolution of Morettian thought in three time segments allows us to also capture an intermediary stage of transition and movement from one paradigm to another, which implies their coexistence and codetermination. In addition, in the 90's, this is precisely what they are. Moretti does not simply pass from one paradigm to the other, when the moment calls for it and provides the necessary instruments. On the contrary, he lays the foundation of the new method. And it is not just a preliminary foundation, drily programmatic, but an already substantial foundation, rich in content, in the Atlas. This, he confesses in the

\footnotetext{
${ }^{1}$ A first part of this investigation, dealing with Moretti's developments in the 1980's and his background in Western Marxism, - "Backtracking Moretti. From Distant Reading to Marxist Aesthetics" - has been published in Romanian in Vatra, no. 8-9, 2020: 61-72. A further essay, dealing with the evolution of Moretti's thinking in the new millennium, his enthusiasm, then bitter disenchantment with 'distant reading' and the relation between his tortuous intellectual path and the trajectory of Western Marxism is currently in the making and will (hopefully) be published next year.

2 See Franco Moretti and Oleg Sobchuk, "Hidden in Plain Sight. Data Visualisation in the Humanities", New Left Review, no. 118, July-August 2019; Franco Moretti, "The Roads to Rome. Literary Studies, Hermeneutics, Quantification”, New Left Review, no. 124, July-August 2020. Moretti's first doubts as to distant reading's materialist ability to detect the relevant social forms in the literary continuum were expressed already in his Stanford Literary Lab pamphlet "Literature, Measured" (April 2016), https://litlab.stanford.edu/LiteraryLabPamphlet12.pdf. But then, considering Moretti's first proper exercise in massive quantitative analysis with computational tools dates from 2009 - the essay "Style, Inc. Reflections on Seven Thousand Titles (British Novels, 1740-1850)", Critical Inquiry, Vol 36, no. 1, Autumn 2009, reprinted in Distant Reading, Verso, London \& New York, 2013 -, one can conclude that, rather surprisingly, the period characterized (not even exclusively, but rather predominantly) by analyses in distant reading using digital tools occupies barely a decade in the long spanning intellectual career of the author who passes as "the leading practitioner and theoretician of distant reading", Liu, for example, describes him (Liu 493.).
} 
Introduction, 3 had been on his mind since 1991. This was the exact same time and interval in which he was perfecting the theoretical model refined in the 80's in Signs Taken for Wonders ${ }^{4}$ and The Way of the World: the Bildungsroman in European Culture $^{5}$. And in a way, Modern Epic is the fulfillment of the analyses and perspectives from previous volumes and not only because it develops or somehow totalizes the topic - the same literary genre - in an entire volume, as opposed to the more essayistic approach to each literary form in Signs, for example. But the totalizing and exhaustive perspective of this close reading investigation manages to exhaust the topic: all of the literary occurrences that constitute and realize this literary genre. This is an achievement in itself, since such a performance is generally forbidden to close reading criticism, which can discuss literary genres and forms only through a limited number of examples and, thus, only the most exceptional ones. Modern Epic is thus a performance of exhaustiveness and totality despite its lack of uniformity (100 pages for Faust and Ulysses each, 20 for The Ring of the Nibelung, The Waste Land and One Hundred Years of Solitude, with the rest of the "opere mondo", world-narratives, being discussed and mentioned in passing), which is constituted and made possible by a great formal intuition: if the impassable limits of close reading analysis are that it is humanly impossible to discuss in detail more than a few dozen literary works, then could one hope to identify a single literary genre which is fully constituted and represented by such a small number of texts? The sparseness of these literary works, the low reproduction rate would have to do specifically with its defining monstrosity: modern epics - i.e., literary attempts to totalize a fundamentally anti-totalizable world, at least in its immediate manifestations and the usual phantasmatic reality, supported as it is by commodity fetishism. The perfect formal cut-out: a micro-world (a manageable multitude) of reflections and projections of whole worlds. This ingenious formal solution is, however, let us admit it, a fortunate intuition, the magical surplus value of conceptual formal analysis, a form he creates for himself, in which the phenomenalizations of the genre can be organized and wonderfully filtered, fully

\footnotetext{
3 "The idea for this work came to me by sheer chance..., during a long car journey in the summer of 1991:... we don't have literary atlases... So - why not try to make one?” (Moretti, Atlas 6).

4 See Franco Moretti, Signs Taken for Wonders. Essays in the Sociology of Literary Forms, Verso, 1988.

5 See Franco Moretti, The Way of the World: the Bildungsroman in European Culture, Verso, 1987.
} 
saturating their nominal genre. ${ }^{6}$ I insist, perhaps too much, on this aspect because it is in perfect contrast with Moretti's bitter reflections 20 years later (i.e., in recent years), in which distant reading is said to be unable to capture the form of the literary continuum and, thus, to propose by itself the relevant forms and concepts that could structure it. Here instead, in the mid-90's, Moretti's old "method" of close reading (although of course it is not strictly a method, but rather a pattern and a relatively elastic combination of formalist rhetorical analysis, evolutionary theory and Marxist metanarrative) produces its most complete realization - even in a mathematical sense at the same time when Moretti was already working all by himself on the first distant reading sample from Atlas. And, let us face it, the demo, private-workshop version of digital humanities in this book is already a big hit.

It is not my intention here to summarize and comment on every nook and cranny of the two volumes, but instead to problematize a few aspects which interest us in this text. And from this perspective, a first observation is implicitly necessary. Although they seem radically opposed from a methodological viewpoint - close reading brought to perfection and completion in Opere-mondo, distant reading still searching for its instruments and concepts, and forging them in Atlas -, the two books actually share and start from the same methodological programme, which had been the defining premise of Moretti's reflections in the 1980's and which would feed into his increasing bitterness towards the productivity of digital humanities techniques in recent years: the possibility and necessity of a materialist literary theory, which would be exactly what its name claims - simultaneously an acknowledgement and a problematization of the autonomy of literary forms, and implicitly a rhetorical-structural analysis; as well as a social interpretation and a functional-historical analysis of these forms. "A materialist history

\footnotetext{
${ }^{6}$ In short, an intellectual intuition: something that, from a philosophical point of view, can hardly exist but which might be in its own element in the field of aesthetics: on the one hand, an analytical effort of the intellect (a "negative" one, then) to discern formal continuities, regularities and discontinuities in the phenomena themselves, but at the same time a positive, intuitive effort, as it imbues each form perfectly with its literary phenomenalizations. Moretti is fully aware of the rather excessive ambition of conceptual surplus-value achieved through this new literary formalization - "the modern epic". According to him, it is a necessary re-categorization of what was much too unstable in the concept of "modernism". Thus, the new concept, the new form proposes a transversal section through modernism - a useless concept by now, because of its eclecticism - and produces a homogenous category of the non-homogenizable: the modern epic. "Very well. But was I not exaggerating a bit? Is it not odd that, in two centuries of history, a form of such importance should notch up only about half a dozen really achieved specimens?" (Moretti, Modern Epic 3).
} 
of literary forms is too splendid a challenge to intelligence to be let slip... in all honesty I know of nothing better, for anyone concerned with literature" (Moretti, Modern Epic 56), says Moretti in the Introduction to Modern Epic. In addition, two or three years later, in Atlas: "Literary form appears thus as the result of two conflicting, and equally significant forces: one working from the outside, and one from the inside. It is the usual, and at bottom the only real issue of literary history: society, rhetoric, and their interaction" (Moretti, Atlas 5).

The same research programme, materialized in two almost contemporary and yet (at least at first glance) methodologically opposed volumes. Nevertheless, their contrast is ultimately dictated by the respective objects of the two investigations: the novel and the anti-novel (as we could call it) represented by the "modern epic". On one hand, then, we have the prolific genre of the novel. It is reproduced in massive numbers and fairly regular forms, and analyzed by Moretti mostly during its period of maximal stabilization and formal hegemony: the nineteenth century. This, according to the essays from Signs Taken for Wonders and The Way of the World, is the century of the Bildungsroman -, a genre which seems to be the image (and the ideological function) of moderation and unflinching realism, typical of bourgeois societies and which, finally, through its very dimensions and rate of uniform reproduction, seems to require a mass, quantitative, and even computational, approach. On the other hand, we have a literary genre exemplified by only a few dozen works, with an extremely low reproduction rate, which, what is more, presents no formal regularity in its occurrences, but merely an identical and unreasonable ambition to produce a total form (an epic) in a modern, nontotalizable world. And this ambition is fairly opposed to the novelistic reasonability of the bourgeois world. A genre, finally, which, because of its extremely rare occurrences and constant formal irregularity, requires - again in opposition to the novel - as close an approach as possible.

The contrast between the two literary forms - the novel and the modern epic carries into other aspects, as well, and the two almost contemporary volumes and research projects are practically built around this opposition. In spite of it, or perhaps

\footnotetext{
7 Moretti had already flirted with this problem of the novel and the anti-novel in Signs Taken for Wonders, where the European space of modern tragedy was seen as the negative of the European novelistic space.
} 
because of this structural opposition between the literary forms, the sporadic overlaps and convergences which occur between the two in Moretti's texts, and precisely at the main junctures, are all the more relevant. First the set of oppositions: while the novel is the expression and literary form of the national state, the modern epic fulfills the same role for the world-system of modern capitalism. While the novel is by definition centripetal, describing a movement (the initiation and the seduction of the protagonist) from province to capital - "the novel is the most centralized of all literary genres", Moretti proclaims at some point (Moretti, Atlas 165) -, the modern epic is centrifugal, a succession of worlds that are only totalized through digression and amalgamation. While the novel is a genre whose expansion and success were massive and spontaneous, thus representing an eminently popular genre, modern epics constitute a purely scholastic genre, as their survival was exclusively ensured by the public educational system - ultimately, the shortest definition of these world-texts is, according to Moretti, that they are "very long and very boring" (Moretti, Modern Epic 4) and that we pretend to have read them only because they are part of any intellectual's canon ${ }^{8}$. And last, but not at all least, there is one more crucial opposition between the worlds and the experiences built by these literary forms: the novel - and especially the Bildungsroman, its essence - articulates, of course, the narrative itself of individual formation and experience, representing therefore a sort of enlightened anthropocentrism which somehow still claims - although in an ever more skeptical, ironic, or subversive manner, but nevertheless compelled by its form to do so - to reconcile subjective action and experience with the immensity and abstract pressure of the modern world, to reintegrate the individual in a world endowed with meaning. On the contrary, the modern epic is, from this perspective, the very form of subjective destitution, with the subject and her/his experience being crushed under the weight and rigidity of the objective spirit and of the modern reified society - almost literally: the spirit becoming

\footnotetext{
8 Moretti does not take the opposition between novel and modern epic very far in terms of their public: the mass popularity of the novel and the selective reception of the epic, sustained only by cultural elites. Were we to push further Moretti's thoughts, we could wonder whether this argument could be the basis of an opposition between the novel and the modern epic not only as the figures of different points in the modern world-system - the metropolis for the novel, the semi-periphery for the modern epic - but also as cultural ideologies belonging to particular classes (or class factions): a sort of popular front made of medium and low classes for the novel vs. a sort of enlightened front of educators and high intellectual bourgeoisie for the modern epic.
} 
(self-alienating itself as) an object and a world-totality of objects which obscure all social relationships and weigh down on the individual.

However, already here - and this is the crux of the issue - these oppositions begin to slide away until they become overlaps, similarities, coincidences. This is because we are not dealing with static forms. Even though they evolve at different paces - slowly but in massive numbers, for the novel, and in radical and constant leaps but within a limited set of works, for the modern epic - they still evolve during the intervals in which they are being studied (the nineteenth century for the novel, the end of the eighteenth century and the first half of the twentieth for the epic), and sometimes end up turning into their opposites. Although Moretti does not problematize in these exact words, it seems that the two forms are describing a symmetrically opposed trajectory. The novel, on the one hand, slowly leaves behind (or attempts to) its defining anthropocentrism, its binary narrative structure, the metaphysics of individual experience and the reconciliation between subject and world, towards "the novel of complexity", through Balzac and classical realism, where the traditional binary narrative scheme is already abandoned, and the third party - which is none other than "social overdetermination", says Moretti - gradually becomes the true main character. At least until the major formal reconfigurations of the novel at the end of the nineteenth century and especially the beginning of the twentieth, where anthropocentrism and the illusion of reintegrating the subject in a disenchanted world appear to have been definitively abandoned, but also - an absolutely relevant fact - formally maintained, in the novelform, although they are being subverted - parodied, allegorized or subverted ironically - in a modernist fashion. The modern epic, on the other hand, has a more winding and less linear evolution, but seen from a distance, its tendencies seem to indicate an opposite dynamic too: from Goethe's Faust, through Wagner's Ring of the Nibelung and up to Joyce's Ulysses, we witness an increasingly radical deconstruction of anthropocentrism and "monologism" and a greater openness to polyphony and subject destitution. Yet immediately after Joyce, with T.S Eliot and, later, One Hundred Years of Solitude by Marquez, there is an abrupt counter-movement of suture, synthesis and reduction of complexity (through mythologization with the former, and through an apparent style zero of narrative purity with the latter, symmetrically opposed to the explosion of styles without narrativity in Ulysses). In short, while the novel transitions 
from its constitutive anthropocentrism to polyphony, the modern epic makes much more irregular leaps, but finally crosses from polyphony to anthropocentrism. Of course, this applies only inasmuch as we can compare and take for granted these evolutionary patterns based on such different samples - and this is one of the basic assumptions of the volumes. Then, if we can indeed summarize and compare the evolution of the novel (in its hundred thousand specimens) with the evolution of the modern epic (in its 20-30 occurrences), how can we explain their mirrored pattern of evolution, all the more so that - as we will soon discover - they have or fulfill the same socio-historical or ideological function?

This brings us to the second, socio-historical side of Moretti's approach and to the already discussed "functional" role of literature in relation to society. If literature is functional in relation to society, perhaps it should not be surprising that different literary forms - specialized in accordance with their formal autonomy - and even apparently opposed ones fulfill the same ideological function of re-enchantment 9 .

The modern epic, for instance, is "an attempt to turn history back, abolishing the excessive complexity of modern societies and restoring the unchallenged dominion of an individual" (Moretti, Modern Epic 13). And towards the end of the book: "The totalitarian temptation is almost always present in the modernist world text, as a reaction to a complexity that has grown beyond every expectation. But it is just a temptation - which never becomes the dominant presence" (Moretti, Modern Epic 228). Through its "desire to reunite what history has torn apart..., the world text rejects the calm agnosticism of the novel: it rebels against the slow decline of the sacred, and seeks to restore lost transcendence" (Moretti, Modern Epic 108-109). In brief, the modern epic is the expression of "the need for re-enchantment" (133), "to create a perceptual order, not a real order" (112). But obviously, the defining function of the novel is the same reduction of polyphony, the re-centering on subjective experience and the re-enchantment of the world: "historical states need historical novels. Nevertheless, need those to do what? To represent internal unevenness, no doubt; and then, to abolish it”, Moretti says in Atlas of the European Novel (40). In Modern Epic, he gives a brief

9 I have dealt more extensively with this social function of reenchantement entrusted to literature by Moretti in the essay quoted above (note 1). 
definition of the novel as "a symbolic brake upon modernity" (195) ${ }^{10}$, thus summarizing and reiterating several analyses from the previous decade. What we have then is an identical socio-ideological function fulfilled by two opposite forms - and which is being realized by each form in its own twisted, diagonal way, or, more technically: according to its own formal rules. It might seem surprising, but it conforms to the theoretical basis already laid by Moretti in his essays from the 80's: a functional-historical reading of literature, which not only allows, but even more so explains, the (relative) autonomy of literary forms and their formal differentiation and specialization in relation to society and the historical context.

However, a problem does seem to appear on the trajectory of this functional relationship between literature and society: it is not entirely clear whether this functional relationship between literature and society, is accomplished when the social factor - society, the historical context, capitalism, we can give it any name, for now really needs literature to do this, or only when it can impose its will? And by this "functional relationship", I mean, in other words, literature assuming the ideological function of reconciling the subject with objectivity and of re-enchanting the world (no matter if this function is diagonal and opaque and capable of re-processing social realities according to the taste and the autonomy of the literary form. Here, Moretti appears to oscillate between the two possible alternatives. According to one of his interpretations of the Darwinian theory of literary evolution - especially in Signs Taken for Wonders and The Way of the World, but also in the volumes published in the 90's it seems that when the capitalist-bourgeois society is stable, we also have a functional stability of the literary genre. The supreme example: the nineteenth-century Bildungsroman. Thus, the explanation is that there is a direct functionality of literature when the social system is strong and consolidated enough to impose it, that is, when it can determine it. But these are also, undoubtedly, the moments when the system needs it the least - precisely because it is stable and consolidated. However, when the

\footnotetext{
${ }_{10}$ The twentieth century, Moretti argues, is polyphonic because anthropocentrism has become impossible in modernity, since the abyss separating objective culture from anthropocentrism - already ripe and in full view by the end of the $18^{\text {th }}$ century - has further increased enormously. However, if anthropocentrism had been already consumed by the end of the eighteenth century, why did modernism emerge so late? Because, Moretti answers, the novel managed to defer it through its modelling function - „a symbolic brake upon modernity". The novel is therefore a deterrent of polyphonic apocalypse and modernism, which are instead being continuously prophesized by the modern epic.
} 
ideological function of literature is truly needed (the re-enchantment of the world), in moments of crisis and historical upheaval, according to the Darwinian scheme, the social system cannot really exert a homogenous and functionalized type of pressure, and literature blooms in a short season of experimentalism and free use of literary forms for the mere sake of it. Thus, according to this narrative, the social system imposes the ideological function of literature when it is able to, because it is increasingly stable and hegemonic, but not necessarily and not always when it needs to. Just like in every-day life, when it can, it is not imperatively necessary; and when it needs to, it is not necessarily possible. But in other parts of these texts, the relationship is altered: for instance, Wagner's trilogy emerged in the midst of the nineteenth century and its triumphant bourgeois society; here, allegory - and a quasi-infinite rhetorical freedom are possible, Moretti says, precisely because capitalism is stronger, thus affording to allow literature a certain freedom, loosening the chains of its ideological functionality. Therefore, this is a case in which the social factor can afford not to employ literature in its ideological function, because it is stable and consolidated enough to need further magical advantage. After all, being able to, but also - or maybe especially - being able not to is the very definition of power, as acknowledged ever since Aristotle: something we can do, but only if we want to, not because we have to or have been constrained to (otherwise, we would not be as powerful). But the same power or "determination in the last instance" of the socio-historical factor can also manifest itself in a third version of the functional relationship, as not being able to when the necessity presents itself: see, for instance, the Ulysses moment, when polyphony and formal freedom reach maximal expansion in the middle of a profound crisis of the early twentieth century bourgeois society. And, generally, it is one of Moretti's recurring arguments (for example at the beginning of Modern Epic [p.19]) that the explosions of autonomy and formal freedom do not conform to any established literary programme, because they do not occur in periods of normal literature, but in moments of crisis and transition: "Plans and poetics function (perhaps) when inside a stable formal paradigm: in times of 'normal' literature, so to speak. But if paradigms are shifting they are a waste of time, because change is not planned: it is the fruit of the most irresponsible and free - the blindest - rhetorical experimentation". 
So, which one is going to be, from these three possible explanations of the functional relation between literature and the social system? Nevertheless, the explanation of this apparent incongruity is extremely simple, Moretti would probably say: our object of study is not a single historical continuum, along a linear history to which all these literary works, either novels or modern epics, supposedly belong. On the contrary, we also need to take into account the places and the geographical distribution of these texts. Not every socio-historical context, be it a synchronic one, is the same, exerting the same pressure, in a single direction. Instead, we are dealing with a worldsystem with an unequal and combined development, with its metropolises, semiperipheries and peripheries. In the metropolis, during the century of bourgeois hegemony, the European novel is intensely codified and functionalized. At least this is the conclusion of the last Atlas essay, about the libraries, translations and the market of the European novel: "While the consumption of fiction was becoming more and more widespread, its production was becoming more and more centralized" (170) - which would eventually happen with mass culture, as well. "With the novel, then, a common literary market arises in Europe. One market: because of centralization. And a very uneven market: also because of centralization... there arises a planetary reproduction of a couple of national literatures" (187); “'Development of underdevelopment' here as well, where "latecomers don't follow the same road of their predecessors, only later: they follow a different, and narrower road. They are constrained to it by the success of the products from the core" - and "where dependence appears - unfortunately - as the decisive force of cultural life" $(191,195)$. Therefore, here, in the functional reading developed in the last chapter of Atlas, the emphasis of the functional relationship is on dependence and coercion, rather than on the freedom of formal specialization. Here, the system can, and accordingly does, impose its formal code. In Modern Epic, however, the same functional relationship emphasizes formal freedom - but a freedom that exists only in brief moments of historical crisis and that, moreover, manifests itself only in semi-peripheral locations of the world-system. It is this intermediary condition, the semi-peripheral one (be it eighteenth and nineteenth century Germany, where the bourgeois revolution had to be brought belatedly from abroad, Ireland in the 1920's, or South America in the 1960's) that facilitates the formal freedom of the modern epic, while also granting it a certain social, or even global relevance, spurring as it does from 
the very intersection of the coordinates of the capitalist world-system. The contexts are therefore quite different: in the metropolis, the novel is hegemonic and literature is more functionally rigid because the social context can make it so; in the semi-periphery, the modern epic is more possible (but its emergence is purely contingent, unpredictable, shows Moretti) because the socio-historical context cannot subordinate the literary space as it sees fit, although it might need it more than anyone, ever.

It is, all in all, a materialist theory of literature which seems to finally justify its label: it is theoretical enough to propose a general pattern of literary evolution and development, but also sufficiently materialist to make room for diverse examples and explain them through the variation of the socio-historical context; and all these while saving the autonomy of literary forms. This autonomy of the literary form is here not only real and genuine, but even more - effective. It manifests itself in the fact that

the form has constructed its own ideology - and a very effective one. But all this is the result of a purely formal dynamic. It was not the primary object of Goethe's work, and rhetoric met history only at the end of the process. But does it really make much difference whether ideology precedes rhetoric or follows it? It makes an enormous difference. For, in the former case, ideology might guide form to the desired end; not so in the latter, since it comes up against the rigidity of readymade rhetorical choices. This is why literary ideology is always somewhat askew in relation to others: because it rests upon a jumble of fortuitous experiments, rhetorical fetters and unpredictable turns (Moretti, Modern Epic 55).

From these perspectives, the last chapter of Modern Epic is, again, especially relevant. While, in the 1980's, Moretti's analyses would usually, towards their end, suddenly leap abruptly into the contemporaneity of mass culture from the most highbrow discussion of modernist literature (and what is more highbrow than Joyce and Eliot?), his work on the modern epic proposes - for the first time - a possible intermediary bridgehead: a midway stop in the 1960's, Latin America and One Hundred Years of Solitude by Marquez. This terminus among the occurrences of the modern epic - but is it truly a terminus? what could come after it? or what has already? -, from which contemporary mass culture will emerge afterwards, is a somehow symmetrical 
inversion of Ulysses. There, we had a contraction of history and an expansion of space (both external - Dublin, and internal - Bloom's stream of consciousness; but also, intersubjective - the polyphony in the second part). With Marquez, there is a maximal contraction of space and an equal expansion of history. From Joyce's polyphony and non-narrative, to Marquez's monologism (non-style) and pure narrativity. Here, too, what is crucial for a functional reading and explanation is the space of enunciation: this non-style, the regaining of literature's lost innocence had to be (re)born in the worldsystem semi-periphery of Latin America, because modernity - with its colonialism, fascism and imperialism - had forbidden this experience and this ambition to the Europeans. This new "rhetoric of innocence" - all modern epics are the expression of this pursuit - could only emerge from the magical world (a semi-peripheral one, both within and without) of Macondo. In this sense, One Hundred Years of Solitude is, according to Moretti, the novel of 1968: a novel devoid of ideology, pure story. Which reveals a more complex relationship between the socio-historical factor and the ideological function of literature: the socio-historical context in itself is split, and the novel is socio-historically "explained" by Moretti in two different ways: it has a reenchantment function, regaining innocence for the Western core, which, in this crucial moment, can and cannot impose such a function on literature: more exactly, it cannot accomplish this on its own, but it becomes able with the aid of the semi-periphery, which must deliver and provide the lost innocence "from the outside" 11 . But for the immediate South-American context of the novel, its "function" or its appearance is explained quite differently. Here, a literary factor seems the decisive one - which corresponds to the structural side of the autonomous form -, but one that still has certain socio-historical roots. It is the fact that the system of world empires, which, through the Inquisition, had forbidden for centuries the printing and distribution of novels in South America, thus allowed or indirectly created a much greater freedom for

\footnotetext{
${ }_{11}$ Michael Caesar, in "Franco Moretti and the World Literature Debate", Italian Studies, vol. 62, no. 1, 2007: 130-131, believes that Moretti's analysis, inspired by Wallerstein's world-system theory, grants the capitalist centre all the agency and action potential, relegating the semi-periphery to a mere reflective, passive position. This is not quite true - but the danger is always there with Moretti, particularly because of the tension between the monism (at least in terms of horizon) of world-system theory, on the one hand, and the contingency or the pluri-causality of Darwinian theory as practiced by Moretti, on the other; and where the ultimate, functional, reading in terms of the former has usually the upper hand.
} 
the literary forms - in the absence of the novel, this one true "predator" and drastic leveler of form, according to Moretti.

Through these diverse functions, adapted to its double context, One Hundred Years of Solitude seems to be a true Hegelian terminus, a final synthesis in this literary history of repeated (and, inherently, semi-failed) epic attempts to re-enchant the modern world. Because here, the metanarrative of world disenchantment through modern technology is turned upside down - or synthesized: it is technology, Moretti shows, that ensures the magic in Marquez's magical realist novel. What Marquez accomplishes - and then functionally delivers to the metropolis, in dire need of reenchantment and recovery - is to re-enchant modernity itself in its most disenchanting aspect: technology, rediscovered as magic. In this manner, Marquez's device in the modern epic repeats or reflects a somehow similar moment from the beginning of Atlas, namely one of the first devices discovered by Moretti in Austen's novels: "the mythic geography - pecunia ex machina - of a wealth that is not really produced, but magically 'found' overseas whenever a novel needs it" (27). From the re-enchantment of capital in the bourgeois novel ${ }^{12}$ to the re-enchantment of technology in the South-American modern epic: the return of the narrative "heals the great divorce between modernism and mass culture" and functionally delivers the necessary magic to capitalism in its moments of structural crisis in the 1960's and 1970's ${ }^{13}$.

Two more remarks are in order. There is a clear and even striking abundance of constant and generally revealing, if not downright pathbreaking intuitions and ideas in both Atlas of the European Novel and Modern Epic. And one of the most exciting of these intuitions has to do undoubtedly with the diverse "devices" 14 discovered by Moretti in the genres he is studying: the already mentioned "pecunia ex machina", i.e.,

${ }_{12}$ But there is no bourgeois novel per se, or, as Moretti says, there is no novel of liberalism: literature is always a diagonal and idiosyncratic expression of the dominant ideology.

13 Was then May 68 an authentic moment - albeit failed - of rupture, crisis, and revolutionary opening? In Moretti's first breakthrough on the international intellectual stage, his early essay with Paolo Flores D'Arcais, "Paradoxes of the Italian Political Crisis", New Left Review, no. 1/96, March-April 1976, Moretti himself seems to suggest it was not, but merely an internal reorganization of the capitalist system and a reshuffling of its superstructure. But what does this mean for the functional autonomy of literary forms? Is it enhanced, or curtailed, genuine or imposed?

14 The device is the main new category introduced by these texts from the 1990's. "It is the device, not the text that is the literary genre's partner in carrying forward the history of symbolic forms. It is the device, once again, that allows us to 'see' literary change... The distribution of the 'very small' (the individual device) thus confirms that of the 'very large' (the different areas of development of epic and novel)", i.e. the historical configuration of the genre. (Moretti, Modern Epic 75-6). 
the innocentization and re-enchantment of primitive capital accumulation; the increased weight of figurality in the novelistic texts of the national state in which the action is placed close to the borders; the figure of the third party as a representation of over determination and social complexity and the implicit central category of the compromise in Balzac's literature - when it comes to the analyses from the Atlas. Or, out of the multitude of examples from Modern Epic: the role of truisms/commonplace ideas from Bouvard...; absentmindedness and the commonplace as epiphany in Ulysses - the last subjective experience allowed in modernity: the subject as a passive, semiencyclopedic, semi-stupid spectator of the world, a "tomb of experience" as an expression of the objectivized spirit and "cultural entropy"; the figure of noncontemporaneity as an experience of progress; the development of underdevelopment typical of the semi-periphery; the device of the "stream of consciousness as the form of the present: the present as the duration of advertising" (136) as employed by Joyce. All these ideas - and many more similar ones - are simply brilliant, but what do they tell us exactly? Usually, they show us the way in which literature reflects, but also refracts and thus solves, at least figuratively or symbolically, a dynamic or a relationship of the real, historical society. Therefore, they tell us something about literature, explaining it through history and sociology. But then, Moretti's promise, already made during the previous decade, of a materialist history and theory of literature, which would not only assist social sciences as a parasite, merely applying their concepts to the literary field, but would also make its own contribution to the corpus of general social knowledge, through its separate field of study, namely literary forms in their autonomy - this promise seems to remain unfulfilled. What Moretti does deliver here is truly remarkable, but it is not yet that surplus socio-historical knowledge that he had promised: it is no coincidence that the set of literary devices problematized in the two volumes always take off from certain concepts or arguments from the same old human and social sciences - Braudel, Wallerstein, Simmel, Adorno, Weber, Lukacs, Marx which he then applies in an inspired, masterly way to literature. Literary theory is still just applying and confirming the instruments and concepts forged in the social sciences 
in order to capture - as well as possible - the richness of the concrete historical moment ${ }^{15}$.

"What can quantitative methods add to the study of literature? They add, first, a richer historical context... a dramatic enlargement of the historian's domain, towards what is everyday, un-monumental, or even invisible", Moretti announces in Atlas of the European Novel (149). But we have not arrived there yet. It is precisely this promise that will sustain - enthusiastically at first, with strong institutional support and increasing international reputation from a certain point on, then with increasing skepticism - Moretti's distant reading analyses in the 2000's, where - at least in Moretti's expectations, as in those of the fans of the new type of criticism - the content or the literary object itself, i.e., the totality of the literary corpus, finally integrated thanks to its digital support, would deliver and dictate its own proper form of reading and interpretation. But in the 1990's, Moretti is not there yet, and thus the critic must still bring these forms with him, engender them by himself, when approaching the text, and try to make a bricolage from the available sources - which conceptually, for what concerns the literary forms and devices, are still imported from the good old materialist tradition of social thought.

Which leads us to a final observation. We were saying, in the opening of this paper, that the two volumes discussed here - Atlas of the European Novel and Modern Epic - employ opposite methods: distant reading vs. close reading. That is not exact. And it's not just the fact that, in some moments, the two volumes borrow each other's methods, as for instance when in Modern Epic Moretti measures the frequency of stimuli in Ulysses (155) or when he compares the lengths of these world-texts (Ulysses vs. The Waste Land), which, he claims, are highly relevant "because the dimensions of a work are not just a quantitative matter, but a formal one", pertaining to different structures altogether (224); or when, alternatively, he often abandons the counting of

\footnotetext{
15 "At bottom, Moretti is neither a literary theorist not a literary historian. He is an historian who happens to deal with literary texts", says Geoffrey Winthrop-Young, in an extended critical review of the volumes discussed here -Atlas of the European Novel and Modern Epic - "How the Mule Got its Tale. Moretti's Darwinian Bricolage", Diacritics, no. 29, vol. 2, 1999, p. 19. Later on, he elaborates this argument, discussing Moretti's attempt to combine a materialist-functional reading with a formalist-rhetorical one: "If literature has a "problem-solving vocation", if it acts as a cultural decongestant to relieve wearisome individuals from "symbolic overload" brought about by social transformations, is there not the danger of materialism gaining the upper hand by infecting a (decidedly non-Darwinian) Lamarkian note?” (32).
} 
signifiers and embarks on close semantic analysis on countless occasions in the Atlas. More important than these occasional and mutual contagions is the fact that in Atlas, which was supposed to be the first Morettian sample of distant reading, reading is not yet as distant or quantitative and digitalized as the paradigm would require it to be, and as the post-2000 texts would programmatically attempt ${ }^{16}$. In Atlas, we get a sort of distant reading without digital humanities (because Moretti counts and draws analogically, by hand, or with rudimentary instruments), or perhaps the opposite, digital humanities without distant reading (because he operates with quantitative, formalizable instruments, but the novelistic corpus is still a limited one, which he counts and captures in devices working as closely as possible). Somewhere between these two quasi-synonymic expressions, we can find Moretti's endeavors in the 1990's. On the move, dialectical, exactly as we expected them to be.

\section{References:}

Caesar, Michael. "Franco Moretti and the World Literature Debate", Italian Studies, vol. 62, no. 1, 2007: 125-135.

Cistelecan, Alex. "Backtracking Moretti. De la distant reading la estetica marxistă", Vatra, no. 8-9, 2020: 61-72.

Liu, Alan. „Where is Cultural Criticism in the Digital Humanities?”, in Mathew C. Gold (ed.), Debates in the Digital Humanities, University of Minessotta Press, 2012 (https://dhdebates.gc.cuny.edu/read/untitled-88c1180o-9446-469b-a3be3fdb36bfbd1e/section/896742e7-5218-42c5-89bo-oc3c75682a2f\#ch29).

Moretti, Franco, The Way of the World: the Bildungsroman in European Culture, Verso, 1987.

---. Signs Taken for Wonders. Essays in the Sociology of Literary Forms, Verso, 1988.

---. Modern Epic. The World-System from Goethe to Garcia Marquez, Verso, 1996.

---. Atlas of the European Novel. 180o-19oo, Verso, 1998.

---. "Style, Inc. Reflections on Seven Thousand Titles (British Novels, 1740-1850)", Critical Inquiry, Vol 36, no. 1, 2009: 134-158.

16 The already quoted review by Winthrop-Young argued that the method employed in Atlas is "a prolonged exercise in 'literary geography' which, at first glance, appears to be the return of close reading in the age of graphics and Rorschach tests" (19-20). 
---. “Literature, Measured”, Stanford Literary Lab Pamphlets, no. 12, April 2016.

---. "The Roads to Rome. Literary Studies, Hermeneutics, Quantification", New Left Review, no. 124, July-August 2020.

Moretti, Franco; Flores D’Arcais, Paolo, "Paradoxes of the Italian Political Crisis", New Left Review, no. 1/96, March-April 1976.

Moretti, Franco; Sobchuk, Oleg, "Hidden in Plain Sight. Data Visualisation in the Humanities", New Left Review, no. 118, July-August 2019.

Winthrop-Young, Geoffrey, "How the Mule Got its Tale. Moretti’s Darwinian Bricolage", Diacritics, no. 29, vol. 2, 1999. 